\title{
The Perceived Waiting Time versus the Actual Drug Waiting Time in the Outpatient Pharmacy at Persada Hospital
}

\author{
Lisa Setiawati $^{1 *}$, Tuti Haryanto ${ }^{1}$, Kurnia Widyaningrum ${ }^{1}$, Agung Putra Jaya ${ }^{2}$ \\ ${ }^{I}$ Master of Hospital Management Study Program, Faculty of Medicine, Brawijaya University, Malang, Indonesia \\ ${ }^{2}$ Persada Hospital Malang, Indonesia
}

ARTICLE HISTORY

Manuscript submission:

January $5^{\text {th }} 2017$

Manuscript acceptance for

review: April $11^{\text {st }} 2018$

Aprroval for publication:

June $26^{\text {th }} 2018$

\section{Keywords :}

outpatient pharmacy, perceived waiting time, uncertainty

\begin{abstract}
A B S T R A C T
The target of quality service for Persada Hospital outpatient pharmacy has been achieved in which the average time spent on waiting for the non-compounded drug is 11 minutes and for the compounded drug is 25 minutes. That achievement has not been able to alter the perceived length of the drug waiting time at the outpatient pharmacy evidenced by the number of losses resulting from unattended prescriptions due to the long wait. This study is aimed to find out and analyze the main factors leading to the perceived length of drug waiting time at the outpatient pharmacy and come up with alternative solutions thereto. The employed method in this study is descriptive qualitative research comprising the observation, interview and the collection of secondary data. The researchers conducted an observation on the process and flow of the prescription service of the outpatient pharmacy and proceeded to the focus group discussion to discover the main problems using Fish Bone Diagram. The uncertain length of the wait time was found to be the major cause. To resolve the issue of the uncertainty of the waiting time, the Time Motion Study was conducted on the service response time as a follow up by providing the estimated waiting duration guide (information) for the outpatient pharmacy. This guide comprises 3 categories of the service waiting time of 10-15 minutes, 25-45 minutes, and 25-60 minutes.
\end{abstract}




\section{Introduction}

As pharmacy constitutes one of the major hospital revenue support units, the patient satisfaction with respect to the prescription service becomes the major concern to the management. Parasuraman (1996) argued that the patient satisfaction with the quality service provided has a huge impact on their loyalty as revealed by their use of the healthcare service. ${ }^{1}$ The patient loyalty has a positive effect on the revenue gained by the hospital.

Persada Hospital is a class B private hospital which provides health care services for non-BPJS patients except for those with the hemodialysis prescription. Based on the secondary data of the outpatient pharmacy, there were 2100 prescriptions on average from July through August 2017. There were 103 lost prescriptions in a month and 45 lost prescriptions on average which were associated with the perceived length of the drug waiting time. The perception did not correspond with the actual drug waiting time that it can be inferred as the patient's subjective perception of the experiences since the prescription service, according to the secondary data of the response time, has basically met the pharmacy minimum service standard. The response time says that the waiting time for non-compounded drug lasts less than 30 minutes (while the standard says that it is less than 45 minutes), whereas the waiting time for the compounded drug lasts less than 45 minutes (the standard is less than 60 minutes).

The perceived waiting time is defined as the act of perceiving associated with the waiting activity in the anticipation of a service. The perceived waiting time when assessed may be biased with the actual waiting time. People may be inclined to sense that they are waiting longer than they actually are. ${ }^{2}$

Maister (1985) stated that 8 factors influence the perceived length of the wait time such as distraction, moment, anxiety, uncertainty, explanation, fairness, value, and solo wait. ${ }^{3}$ The absence of distraction during the wait leads to the longer wait time perceived than the actual one. The process of waiting feels longer when the flow of service is quite intricate (moment) and worsened by the patient's feeling of unease or nervousness which is the so-called anxiety. Uncertain waits and the unexplained process experienced in the wait tend to increase the perceived waiting time. The unfair queues or the equity problem in the queue management affects the perceived waiting time. Value is defined as the perceived value of a product or service that adds to the longer time the process takes than it actually is. The last factor is the solo wait which makes it feel longer than when waiting in a group.

The purpose of this study is to find out, based on Maister's Theory (1985) factors responsible for the increase of perceived drug waiting time at the outpatient pharmacy unit and to seek alternative solutions to the root problems thereof. It is expected that the result of this research provides solution to the alteration of the patient perception of the drug waiting time that prescription loss due to the long waiting time may be prevented from recurring.

\section{Method}

This qualitative descriptive study was conducted from early September to mid October 2017. In this study the instrument was the researchers themselves. The data were gathered from the observation, interview and secondary data of outpatient pharmacy. The leading cause of the problem was then established by the use of the USG method on the first discussion group that was done with the outpatient pharmacy of 8 people including the researchers. The problems identified with the outpatient pharmacy using the USG method are the unattended prescriptions at the outpatient pharmacy unit, the patient's perceived length of the drug waiting time, and the frequently depleted drug stocks. The highest score which points out the main problem is the patient's perceived length of the drug waiting time which is investigated further using the Fish Bone Diagram Analysis. Through the McNamara analysis on the second group discussion with the outpatient pharmacy staff the alternative solutions to problems were obtained. Since the highest score pointed out the need for the drug waiting time estimation, further study was further conducted on the response time to come up with the drug waiting time estimation. Alternative solutions with the highest scores were studied using Time Motion Study and elaborated in an action plan for the implementation thereof. The Time Motion Study conducted on the service response time to all outpatients involved 4 zones such as billing zone, labeling zone, dispensing zone and distribution zone.

\section{Result and Discussion}

The first group discussion was conducted with USG method to discover the main problems using the Fish Bone Diagram Analysis including the following factors: Patient, the prescribing Doctor, Pharmacy service personnel (Man), the unavailability of queuing system programs and E-prescriptions (Machines); the absence of estimated waiting time information, prescription procedure and queuing system (Methods), the absence of diversions, the waiting environment and conditions (Materials).

The Man factor revealed in FGD goes as follows: "Patients frequently request for the prescription to be redeemed outside of the pharmacy because they are in a hurry. Some dread the long waiting time associated with the waiting line in spite of the fact that it takes less than 30 minutes to prepare the compounded medicine". It can therefore be inferred that the patient perceived drug waiting time was different from the actual waiting time. Research conducted by Jones and Peppiat (1996) revealed that the perceived waiting time differed from the actual waiting time $^{2}$ by $40 \%$. Another influential factor is that no certainty is given by the pharmacy concerning the length of the drug waiting time as evidenced by this phrase: "We do not know for sure about how long the waiting for the drug will last while many patients repeatedly question how long the service will keep them waiting toward the completion." 
Table 1. Main problems identification using the 5 why analysis

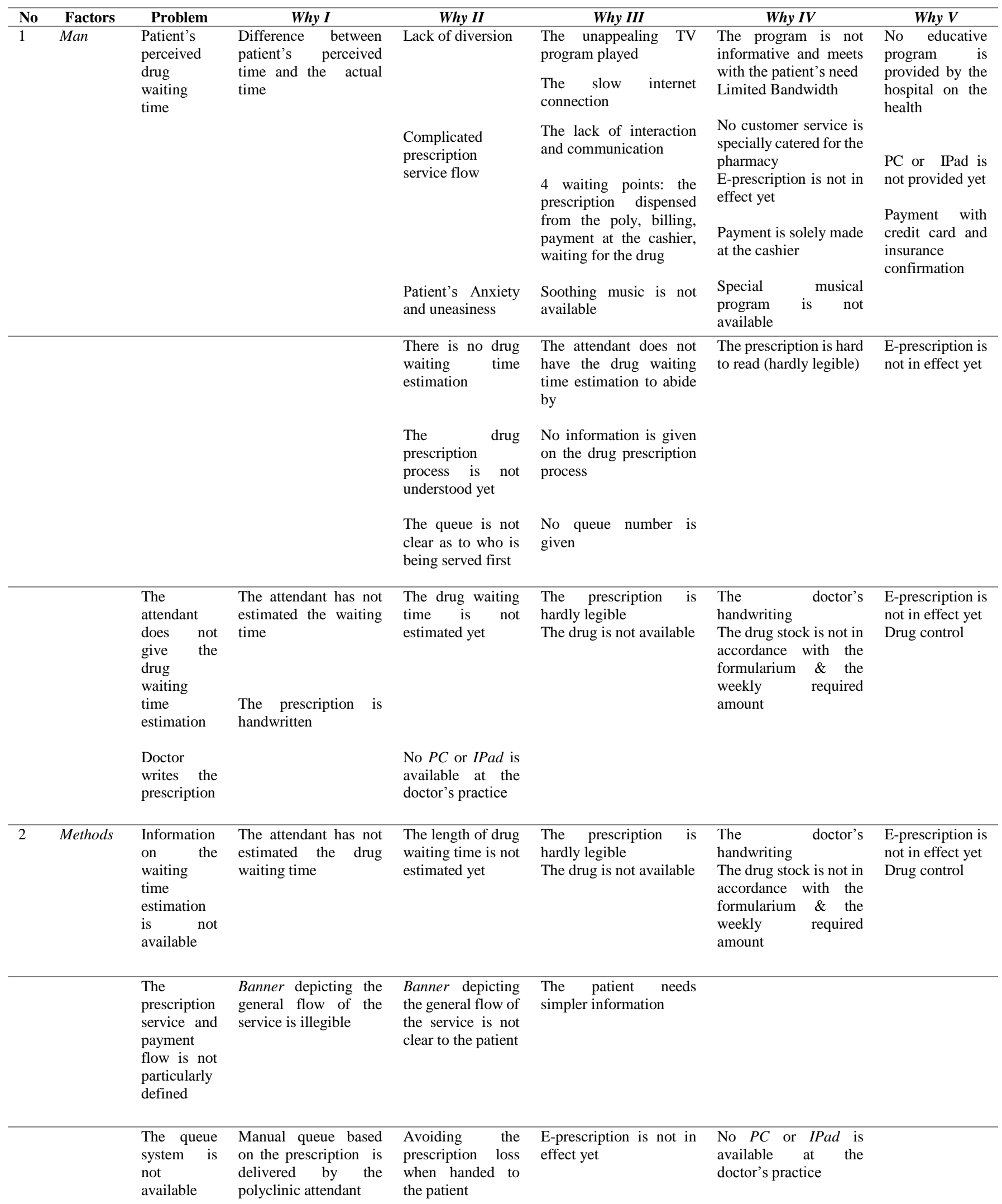




\begin{tabular}{|c|c|c|c|c|c|c|c|}
\hline No & Factors & Problem & Why I & Why II & Why III & Why IV & Why V \\
\hline \multirow[t]{5}{*}{3} & Materials & $\begin{array}{l}\text { The waiting } \\
\text { room is not } \\
\text { visually } \\
\text { appealing }\end{array}$ & The view is dull & $\begin{array}{l}\text { It looks out over } \\
\text { the prescription } \\
\text { counter }\end{array}$ & & & \\
\hline & & $\begin{array}{l}\text { Diversion is } \\
\text { lacking }\end{array}$ & $\begin{array}{l}\text { TV program is not } \\
\text { informative and does } \\
\text { not meet with the } \\
\text { patient's need } \\
\text { Slow internet } \\
\text { connection } \\
\text { Lack of Interaction and } \\
\text { communication }\end{array}$ & $\begin{array}{l}\text { No educative } \\
\text { program is } \\
\text { provided by the } \\
\text { hospital on the } \\
\text { health } \\
\text { Limited } \\
\text { Bandwidth } \\
\text { customer service } \\
\text { special for } \\
\text { pharmacy is not } \\
\text { available }\end{array}$ & & & \\
\hline & & $\begin{array}{l}\text { Environme } \\
\text { nt is not } \\
\text { cozy }\end{array}$ & $\begin{array}{l}\text { Lack of audio or } \\
\text { musical stimulus that } \\
\text { soothes the soul }\end{array}$ & $\begin{array}{l}\text { No special musical } \\
\text { program is } \\
\text { available }\end{array}$ & & & \\
\hline & & & $\begin{array}{l}\text { The environment is } \\
\text { awkward }\end{array}$ & $\begin{array}{l}\text { Patients look out } \\
\text { over the } \\
\text { prescription } \\
\text { counter attendant }\end{array}$ & $\begin{array}{l}\text { The seats are arranged to } \\
\text { look over prescription } \\
\text { counter attendant }\end{array}$ & & \\
\hline & & Furniture & $\begin{array}{l}\text { Seat arrangement is not } \\
\text { comfortable }\end{array}$ & The view is dull & $\begin{array}{l}\text { The seats are arranged to } \\
\text { look over prescription } \\
\text { counter attendant }\end{array}$ & & \\
\hline \multirow[t]{2}{*}{4.} & Machines & $\begin{array}{l}\text { E- } \\
\text { prescription } \\
\text { is not in } \\
\text { effect yet }\end{array}$ & $\begin{array}{l}\text { No PC or IPad is } \\
\text { available at the } \\
\text { doctor's practice }\end{array}$ & & & & \\
\hline & & $\begin{array}{l}\text { Automated } \\
\text { queue } \\
\text { system is } \\
\text { not } \\
\text { available }\end{array}$ & $\begin{array}{l}\text { The manual queue } \\
\text { based on the } \\
\text { prescription is } \\
\text { accepted from the } \\
\text { polyclinic attendant }\end{array}$ & $\begin{array}{l}\text { Avoiding the } \\
\text { prescription loss } \\
\text { when handed to } \\
\text { the patient }\end{array}$ & $\begin{array}{l}\text { E-prescription is not in } \\
\text { effect yet }\end{array}$ & $\begin{array}{l}\text { No PC or IPad is } \\
\text { available at the } \\
\text { doctor's practice }\end{array}$ & \\
\hline
\end{tabular}

The waiting time is perceived to be longer when there is no time certain estimation given by the pharmacy personnel. Kurt Lewin in the book "The Field Theory" (1946) said this in the same vein that the unstructured and unsettled situation leads to discomfort since there is no knowing whether the goal is accomplished or not. ${ }^{4}$

Machine and method factors are equally related to the absence of the estimated waiting time which pharmacy personnel are supposed to give to the patient. Materials point to the condition where there is no distraction despite the installment of television in the waiting room. The seats in the waiting room are exactly opposite the cashier's counter where the personnel appears to be relatively less busy, which is for the patients waiting for the services, a disagreeable sight to look at. This is according to Maister (1985) like a bank clerk busy working on documents, yet he is not seen as acceptably performing the service act to the customers. ${ }^{5}$

Environmental factor encompasses the deficiency of soothing music which is played to alleviate the anxiety patients that causes the actual waiting time to be perceived as longer. This is in line with research conducted by Tansik and Routhieaux (1997) which stated that the relaxing music in the waiting room can effectively alleviate the stress and enhance the positive effect of relaxation than when it is devoid of music. ${ }^{6}$ The Fish Bone diagram analysis result in terms of four factors revealed that the main problem is the uncertainty of estimated waiting time.

The next stage was to establish the alternative solution to the main problem using McNamara analysis (Table 2). This was done by holding the second group discussion with outpatient pharmacy which resulted in the making of the card and guide in terms of the waiting duration The guide to the estimated waiting duration was created by conducting observation, interview and analysis on the pharmacy prescription using Time Motion Study. The observation and analysis resulted in the estimating of discrete drug waiting durations which are set forth in a table for the compounded and non-compounded drug service. 
Table 2. McNamara Alternative Solutions

\begin{tabular}{|c|c|c|c|c|c|}
\hline No & Alternative Strategy & Effectiveness & Efficiency ( cost) & Degrees of Ease & Total \\
\hline 1 & $\begin{array}{l}\text { Educative Video making on the health and hospital } \\
\text { highlights for promotional purposes }\end{array}$ & 22 & 20 & 27 & 69 \\
\hline 2 & Augmenting the internet bandwidth & 21 & 20 & 21 & 62 \\
\hline 3 & Arrangement of the seats in the waiting room & 26 & 25 & 28 & 79 \\
\hline 4 & Outpatient pharmacy customer service & 21 & 19 & 19 & 59 \\
\hline 5 & The Banner depicting the prescription service flow & 29 & 27 & 29 & 85 \\
\hline 6 & Special music program & 25 & 25 & 26 & 76 \\
\hline 7 & Facilitating the E-Prescription program & 30 & 28 & 24 & 82 \\
\hline 8 & Cash payment system at the outpatient pharmacy & 28 & 28 & 25 & 81 \\
\hline 9 & Drug waiting time estimation & 30 & 29 & 29 & 88 \\
\hline 10 & Digital queue system & 26 & 23 & 26 & 75 \\
\hline
\end{tabular}

The differentiation of the compounded drug is based on the number of prescribed items in a single prescription service. The guide serves as the reference to the distribution of the waiting duration card to the patients to which billing personnel must turn for guidance. Time Motion Study conducted on all outpatient pharmacy prescriptions dated from October $1^{\text {st }}$ to October $15^{\text {th }}, 2017$ revealed that the average waiting time for non-compounded drug is 11 minutes encompassing the printing of the drug package to the dispensing of the drug to patients. The average waiting time for compounded drug in a single prescription service actually varies. But, the average time for the drug waiting time is 25 minutes. The difference of waiting duration based on the number of drug items are categorized into as follows: the wait time of $25-45$ minutes for drug item number $1,2,3,5,6$; the wait time of $25-60$ minutes for the drug item number 2 which is the prescription issued by polyclinic specialist because it is usually prescribed for one month medication.
The wait time of $25-60$ minutes applies to the drug item number 4 because the prescription thereof is usually issued by the general polyclinics which constitute the most prescribed drug that often pours in simultaneously. So is true with the following drug item number 7 and so forth.

These three categories of the estimated waiting duration serve as a guide which provides information concerning the estimated drug waiting time in the outpatient pharmacy. The information is presented in the form of estimated drug waiting time indicated in different colors in accordance with the categories of the drug waiting duration set forth in the guide (Table 3).

How to utilize the guide to the estimated drug waiting duration is elaborated in the action plan for the implementation of the solution. It will be carried out in the Persada Hospital outpatient pharmacy in accordance with the activity schedule, executive committee, and the ones responsible for activities, policies, and budget making.

Table 3. Guide to the estimated drug waiting duration in an outpatient pharmacy

\begin{tabular}{|c|c|c|c|c|c|c|c|c|c|c|c|c|}
\hline \multirow[t]{2}{*}{ No } & \multirow[t]{2}{*}{ Type } & \multirow{2}{*}{$\begin{array}{l}\text { Non- } \\
\text { compounded } \\
\text { drug }\end{array}$} & \multicolumn{10}{|c|}{ Compounded drug } \\
\hline & & & $1 \mathrm{R} /$ & $2 \mathrm{R} /$ & $\begin{array}{l}2 \mathrm{R} / \\
\text { poly } \\
\text { spes }\end{array}$ & $3 \mathrm{R} /$ & $4 \mathrm{R} /$ & $5 \mathrm{R} /$ & $6 \mathrm{R} /$ & $7 \mathrm{R} /$ & $8 \mathrm{R} /$ & $\begin{array}{c}\text { 9R/ } \\
\text { so } \\
\text { forth }\end{array}$ \\
\hline 1 & Blue Card & V & & & & & & & & & & \\
\hline 2 & Pink Card & & V & V & & $\mathrm{V}$ & & V & $\mathrm{V}$ & & & \\
\hline 3 & Yellow Card & & & & $\mathrm{V}$ & & $\mathrm{V}$ & & & $\mathrm{V}$ & $\mathrm{V}$ & $\mathrm{V}$ \\
\hline
\end{tabular}




\section{References}

1. Umi K. L., Zeithaml VA, Berry LL, Parasuraman A. The behavioral consequences of service quality. the Journal of Marketing. 1996:31-46.

2. Jones P, Peppiatt E. Managing perceptions of waiting times in service queues. International Journal of Service Industry Management. 1996; 7(5):47-61.

3. Durrande-Moreau A. Waiting for service: ten years of empirical research. International Journal of Service Industry Management. 1999; 10(2):171-194.

4. Dube-Rioux L, H. Schmitt B, Leclerc F. Consumers reactions to waiting: when delays affect the perception of service quality. Advances in Consumer Research. 1989; 16:59-63.

5. H. Maister D. The psychology of waiting lines. Online.; 2005 [updated. www.davidmaister.com

6. Tansik DA, Routhieaux R. Customer stress-relaxation: the impact of music in a hospital waiting room. International Journal of Service Industry Management. 1999; 10(1):68-81. 